\title{
Editorial
}

\section{Saúde e solidariedade: uma aliança indissociável}

Health and solidarity: an inseparable aliance

Salud y solidaridad: una alianza inseparable

\section{Sandra Mara Campos Alves ${ }^{1}$}

\section{Resumo}

A interdependência do direito à saúde com direitos sociais e econômicos pode gerar um círculo virtuoso ou afetar gravemente tais direitos. As ações de cooperação entre os países refletem, portanto, a solidariedade necessária para a garantia e proteção do direito à saúde no mundo.

\section{Palavras-chave}

Saúde global. Solidariedade. Cooperação internacional.

\section{Abstract}

The interdependence of the right to health with social and economic rights can generate a virtuous circle or seriously affect those rights. Thus, cooperation between countries reflects the solidarity necessary to guarantee and protect the right to health worldwide.

\section{Keywords}

Global health. Solidarity. International cooperation.

\section{Resumen}

La interdependencia del derecho a la salud con otros derechos sociales y económicos puede generar un círculo virtuoso o afectar seriamente esta lista de derechos. Las acciones de cooperación entre países, portanto, reflejan la solidaridad necesaria para garantizar y proteger el derecho a la salud en el mundo.

\section{Palabras clave}

Salud global. Solidaridad. Cooperación internacional.

A saúde é componente essencial na vida humana, e os governos estruturam seus sistemas de saúde para poder prover, aos seus cidadãos, ações e serviços voltados à promoção, prevenção e recuperação da saúde. Contudo, as desigualdades econômicas afetam diretamente o binômio necessidade-oferta, seja no âmbito interno, seja entre países, influenciando o tipo de resposta que os sistemas de saúde podem ofertar $(1,2)$.

Desejo ambicioso de transformações profundas dos governos e da própria humanidade foi evidenciado quando da proclamação da Agenda 2030 pela Organização das

\footnotetext{
${ }^{1}$ Doutora; editora-chefe, Cadernos Ibero-Americanos de Direito Sanitário; pesquisadora, Programa de Direito Sanitário (Prodisa), Fundação Oswaldo Cruz, Brasília, Distrito Federal, Brasil. https://orcid.org/0000-0001-6171-4558. E-mail: smcalves@gmail.com
} 
Nações Unidas (ONU), em 2015, objetivando a erradicação da pobreza e promoção de um desenvolvimento econômico, social e ambiental. Dela decorrem os Objetivos de Desenvolvimento Sustentável (ODS), que já destacavam a criticidade do acesso a medicamentos e vacinas seguros e eficazes.

Com a aprovação, pelas agências reguladoras mundiais, de vacinas que apresentaram eficácia no combate ao vírus SARS-CoV-2, observou-se a corrida dos países na aquisição desse precioso e ainda escasso produto, necessário não apenas para a retomada das condições sanitárias como também da economia. Mais uma vez, os efeitos da desigualdade econômica refletiram no direito à saúde, com a aquisição das primeiras doses pelos países ricos. No entanto, a pandemia e seus efeitos - sanitários, econômicos e sociais - não são mitigados de modo individual, exigindo uma resposta global coordenada.

Na contramão de atuações competitivas, houve a formação de aliança que reuniu a academia, setor privado e governos, com o objetivo de acelerar o desenvolvimento, produção e acesso equitativo a testes, tratamentos e vacinas contra a COVID-19. Liderado pela Organização Mundial da Saúde (OMS) e coordenada pela Gavi, The Alliance, tal iniciativa foi batizada como Access to COVID-19 Tools Accelerator (ACT-Accelerator), sendo o COVID-19 Vaccines Global Access (COVAX), o pilar responsável pela área de vacinas, que congrega um portfólio de inúmeras iniciativas, algumas já em uso, e outras ainda em desenvolvimento (3).

Os primeiros frutos dessa colaboração público-privada já começam a ser observados com a distribuição de doses de vacinas nos continentes africano (Costa do Marfim, Gana, Sudão, Quênia, Senegal, Lesoto, Nigéria, Angola, Ruanda, Gâmbia), asiático (Camboja, Coréia do Sul, Índia) e americano (Colômbia), sendo considerado um verdadeiro marco no contexto da saúde global, especialmente por tentar equacionar as grandes desigualdades econômicas que refletem na saúde dos povos (4).

$\mathrm{Na}$ ótica do sistema internacional de proteção de direitos humanos, a saúde é compreendida não apenas no seu aspecto individual, mas interligada a outros direitos sociais e econômicos (5-7). Essa interdependência pode causar um círculo virtuoso ou afetar gravemente esse rol de direitos a depender do grau de proteção e implementação do direito à saúde, sendo a cooperação internacional mencionada como mecanismo que os Estados devem lançar mão para garantir o cumprimento de obrigações de saúde (8).

A Declaração Universal de Direito Humanos, marco na concepção contemporânea do tema, foi concebida com o propósito de estabelecer novos paradigmas, após um período 


\section{Como citar este artigo}

Alves SMC. Saúde e solidariedade: uma aliança indissociável. Cadernos Ibero-Americanos de Direito Sanitário. 2021 jan./mar.;10(1):09-12.

https://doi.org/10.17566/ciads.v10i1.774 